3-1-2016

\title{
Increased Mortality with Elevated Plasma Endothelin-1 in Acute Heart Failure: An ASCEND-HF Biomarker Substudy
}

\author{
Antonio L. Perez \\ Heart and Vascular Institute \\ Justin L. Grodin \\ Heart and Vascular Institute \\ Yuping Wu \\ Cleveland State University, y.wu88@csuohio.edu \\ Adrian F. Hernandez

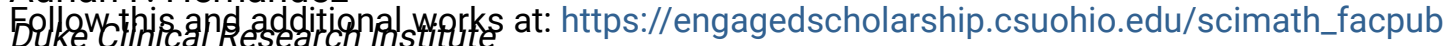 \\ Part of the Mathematics Commons \\ Javed Butler \\ stoHydoroskegfivss thy this work benefit you? Let us know!

\section{Publisher's Statement}

This is the accepted version of the following article: A. L. Perez et al. "Increased mortality with

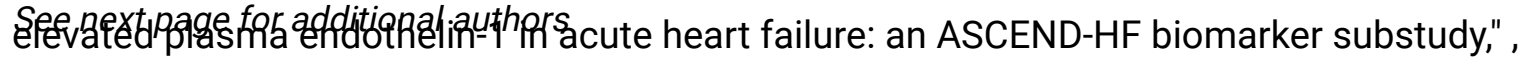
European Journal of Heart Failure, vol. 18, no. 3, pp. 290-297, 2017, which has been published in final form at http://onlinelibrary.wiley.com/doi/10.1002/ejhf.456/full

\section{Repository Citation}

Perez, Antonio L.; Grodin, Justin L.; Wu, Yuping; Hernandez, Adrian F.; Butler, Javed; Metra, Marco; Felker, Michael G.; Voors, Adriaan A.; McMurray, John J.; Armstrong, Paul W.; Starling, Randall C.; O'Connor, Christopher M.; and Tang, W. H. Wilson, "Increased Mortality with Elevated Plasma Endothelin-1 in Acute Heart Failure: An ASCEND-HF Biomarker Substudy" (2016). Mathematics Faculty Publications. 202. https://engagedscholarship.csuohio.edu/scimath_facpub/202

This Article is brought to you for free and open access by the Mathematics and Statistics Department at EngagedScholarship@CSU. It has been accepted for inclusion in Mathematics Faculty Publications by an authorized administrator of EngagedScholarship@CSU. For more information, please contact library.es@csuohio.edu. 
Authors

Antonio L. Perez, Justin L. Grodin, Yuping Wu, Adrian F. Hernandez, Javed Butler, Marco Metra, Michael G. Felker, Adriaan A. Voors, John J. McMurray, Paul W. Armstrong, Randall C. Starling, Christopher M.

O'Connor, and W. H. Wilson Tang

This article is available at EngagedScholarship@CSU: https://engagedscholarship.csuohio.edu/scimath_facpub/202 


\title{
Increased mortality with elevated plasma endothelin-1 in acute heart failure: an ASCEND-HF biomarker substudy
}

\author{
Antonio L. Perez, Justin L. Grodin, Yuping Wu, Adrian F. Hernandez, \\ Javed Butler, Marco Metra, G. Michael Felker, Adriaan A. Voors, \\ John J. McMurray, Paul W. Armstrong, Randall C. Starling, \\ Christopher M. O'Connor, and W. H. Wilson Tang
}

\begin{abstract}
Aims
Endothelin-1 (ET-1) is an endogenous vasoconstrictor implicated in pulmonary and systemic hypertension, as well as ventricular dysfunction, through effects on vascular smooth muscle, the kidneys, and cardiomyocytes. We aimed to determine the association between serial ET-1 levels and acute heart failure patient outcomes.

Methods and results

We measured plasma ET- 1 at baseline, $48-72 \mathrm{~h}$, and 30 days in a cohort of 872 patients hospitalized with acute heart failure from the ASCEND-HF trial (randomized to nesiritide vs. placebo), and its association with 30-day mortality, 180-day mortality, in-hospital death or worsening heart failure, and 30-day mortality or rehospitalization. Median ET-1 was 7.6 [interquartile range (IQR) 5.9-10] pg/mL at baseline, 6.3 (IQR 4.9-8.1) pg/mL at 48-72 h, and 5.9 (IQR 4.7-7.9) pg/mL at 30 days $(P<0.001)$. Baseline and $48-72 \mathrm{~h} \mathrm{ET-1}$ were found to be independently associated with 180-day mortality in a multivariable analysis [hazard ratio $(\mathrm{HR}) 1.6,95 \%$ confidence interval $(\mathrm{Cl})$ 1.3-2.0, $P<0.001$ and HR 1.5, 95\% Cl 1.2-1.9, $P=0.001$, respectively, log-transformed]. ET-1 that was measured at 48-72 $\mathrm{h}$ was also independently associated with death or worsening heart failure prior to discharge [odds ratio (OR) $1.6,95 \% \mathrm{Cl} 1.03-2.4, P=0.03]$. These independent associations remained significant after including NT-proBNP in the multivariable analysis.
\end{abstract}

Conclusions We observed an independent association between elevated ET-1 and short-term in-hospital clinical outcomes and 180-day mortality in hospitalized patients with acute heart failure ET-1 provided additional prognostic information which was incremental to that yielded by NT-proBNP.

Keywords Endothelin-1, Acute heart failure, Prognosis

\section{Introduction}

Endothelin-1 (ET-1) is a highly potent endogenous vasoconstrictor that has previously been implicated in the pathophysiology of congestive heart failure, pulmonary hypertension, and systemic hypertension. ${ }^{1-3}$ ET-1 is produced and released predominantly by vascular endothelial cells and stimulates contraction of vascular smooth muscle, as well as cardiomyocytes, via interaction with endothelin receptors on muscle cell surfaces. In patients with chronic heart failure, circulating plasma ET-1 is detectable at high 
levels, correlates with clinical severity, ${ }^{1,4,5}$ and is associated with mortality. ${ }^{6-8}$ Understanding changes in ET-1 during acute decompensated heart failure (ADHF) may help identify a subgroup of patients who are high risk for adverse clinical outcomes. Furthermore, it is possible that this high risk subgroup may benefit from therapies that interfere with ET-1 production or signalling, including relaxin receptor agonists. ${ }^{9}$ In the hope of further exploring some of these possibilities, we examined the relationship of baseline and serial ET-1 measurements with mortality, worsening heart failure, and rehospitalization in hospitalized patients with ADHF who were part of the Acute Study of Clinical Effectiveness of Nesiritide in Decompensated Heart Failure (ASCEND-HF) biomarker substudy. In this observational, hypothesis-generating analysis, we also assessed ET-1's potential prognostic role in relation to acute heart failure biomarkers, including NT-proBNP.

\section{Methods}

\section{Study population}

The ASCEND-HF trial was a multicentre randomized double-blind placebo-controlled trial that evaluated the effects of nesiritide, a recombinant BNP and vasodilator, in patients hospitalized with ADHF. We excluded patients with clinical evidence of acute coronary syndrome or baseline cardiac troponin $>5$ times the upper reference limit, as measured by the local clinical laboratory. The design and primary results of ASCEND-HF have been previously reported. ${ }^{10,11}$ Studies assessing cardiac troponin I ( $\mathrm{cTnl}$ ), high-sensitivity C-reactive protein (hsCRP), and cystatin $C$ in acute heart failure using subcohorts from ASCEND-HF have been previously published. ${ }^{12-14}$ Out of 7411 patients randomized in ASCEND-HF, our biomarker study enrolled 872 patients in whom ET-1 was measured from serial venous blood sampling at baseline, $48-72 \mathrm{~h}$ after therapy initiation, and at a 30-day follow-up visit. Blood samples were collected in EDTA-plasma between June 2008 and September 2010. They were immediately centrifuged and stored at -80 ${ }^{\circ} \mathrm{C}$ for subsequent analysis at a core laboratory.

\section{Endothelin-1 measurement}

Circulating plasma ET-1 levels were measured from plasma samples taken at baseline $(n=872), 48-72 \mathrm{~h}(n=691)$, and 30 days $(n=643)$. Measurements were performed using the Erenna ${ }^{\circledR}$ Immunoassay Sys-tem (Singulex, Inc., Alameda, CA, USA), which is based upon single molecule counting technology. ${ }^{15}$ Specifically, $100 \mu \mathrm{L}$ of assay buffer with paramagnetic microparticles $\left(1 \mu \mathrm{m}\right.$, Dynabeads ${ }^{\circledR}$ MyOne $^{\mathrm{TM}}$, Life Technologies) coated with capture antibody (MAB3440, R\&D Systems, Minneapolis, MN, USA) were added to each well in a 96-well plate; 100 $\mu \mathrm{L}$ assay samples were added to each well in the plate. The plate was

covered and incubated for $2 \mathrm{~h}$ at $25^{\circ} \mathrm{C}$. The plate was then washed to remove unbound material, and a magnetic bed (Ambion) was used to retain the microparticles in the well. Then, $20 \mu \mathrm{L}$ of detection antibody (MA3005, R\&D Systems) with Alexa Fluor ${ }^{\circledR}$ label were added to each well. The plate was covered and incubated for $1 \mathrm{~h}$ at $25^{\circ} \mathrm{C}$ and washed. The magnetic bed was used to retain microparticles in the well, and was transferred to a fresh 96-well plate, and the bound detection antibody was released from the microparticles via elution with $10 \mu \mathrm{L}$ of glycine. Glycine buffer, containing Alexa Fluor dye-labelled detection antibody (MA3005, R\&D Systems), was transferred to a 384-well receptacle plate containing $10 \mu \mathrm{L}$ of $0.5 \mathrm{M}$ Tris buffer. The microparticles were retained in the 96-well plate via magnetic separation using the magnetic bed. The 384-well plate was read in the Erenna system to count individual Alexa Fluor dye-labelled detection antibody molecules from each well. The limit of detection for this ET-1 assay was $0.07 \mathrm{pg} / \mathrm{mL}$ and the lower limit of quantification was $0.175 \mathrm{pg} / \mathrm{mL}$. Intra-assay precision ( 20 replicates) was $3 \%$ at $11.4 \mathrm{pg} / \mathrm{mL}$, and interassay precision (five assay runs) was $7 \%$ at $7.8 \mathrm{pg} / \mathrm{mL}$. This assay measures the active form of ET-1. In testing to assess ET-1 sample integrity in human plasma, ET-1 showed no signal loss after 9 months of storage at -70

${ }^{\circ} \mathrm{C}$. Freeze-thaw testing revealed no signal loss after seven cycles. Our samples were thawed only once previously for aliquoting from original tubes and shipping. All ET-1 measurements were performed in 2014. NT-proBNP levels were determined by the clinically available VITROS ${ }^{\circledR}$ NT-proBNP Assay (Ortho-Clinical Diagnostics, Raritan, NJ, USA).

\section{Clinical endpoints}

The composite of death or recurrent heart failure hospitalization within 30 days of randomization was a primary endpoint in the overall ASCEND-HF trial. Death and worsening heart failure were assessed together as a composite secondary endpoint and all events were adjudicated to 180 days. In this biomarker substudy, we analysed the following adjudicated outcomes: death at 30 days; death or rehospitalization at 30 days; death at 180 days; and death or worsening heart failure prior to discharge (Supplementary material online, Table S1).

\section{Statistical analyses}

Baseline characteristics were presented as median [interquartile range (IQR)] for continuous variables and as a percentage for categorical variables. The Jonckheere-Terpstra and Cochran-Armitage trend tests were used to assess the significance of a trend across increasing tertiles of ET-1 for continuous and categorical variables, respectively. Two-sided $P$-values $<0.05$ were considered statistically significant. ET-1 levels were not normally distributed, and therefore were expressed as log-transformed. Baseline and follow-up ET-1 levels were compared between patients randomly assigned to placebo or nesiritide via the Wilcoxon rank sum test. The association between continuous, log-transformed ET-1 and intermediate outcomes was performed via logistic regression analyses for in-hospital death or worsening heart failure. The association between log-transformed ET-1 and long-term outcomes was performed via Cox proportional hazards models for the endpoints of 30-day mortality, 180-day mortality, in-hospital death or worsening heart failure, and 30-day mortality or rehospitalization. For multivariable analyses, hazard ratios (HRs) and odds ratios (ORs) were adjusted for covariates that were previously identified for the overall ASCEND-HF study population (ASCEND-HF risk model, Supplementary material online, Table S1). Age, systolic blood pressure $<140 \mathrm{mmHg}$, and blood urea nitrogen (BUN) were used as covariates in multivariable analyses assessing possible associations between ET-1 and 180-day mortality. To assess if the addition of ET-1 to the ASCEND-HF risk model improves outcome prediction, we calculated the area under the receiver operating characteristic curve (AUC), integrated discrimination improvement (IDI), and category-free net reclassification improvement (NRI). NT-proBNP, cystatin C, hsCRP, and cTnl were also included as additional covariates in secondary multivariable analyses. The Kaplan-Meier method was used to compare 180-day mortality across groups. Statistical analyses were performed using $\mathrm{R}$ software (Version 3.1.2, Vienna, Austria). 
Table 1 Baseline characteristics

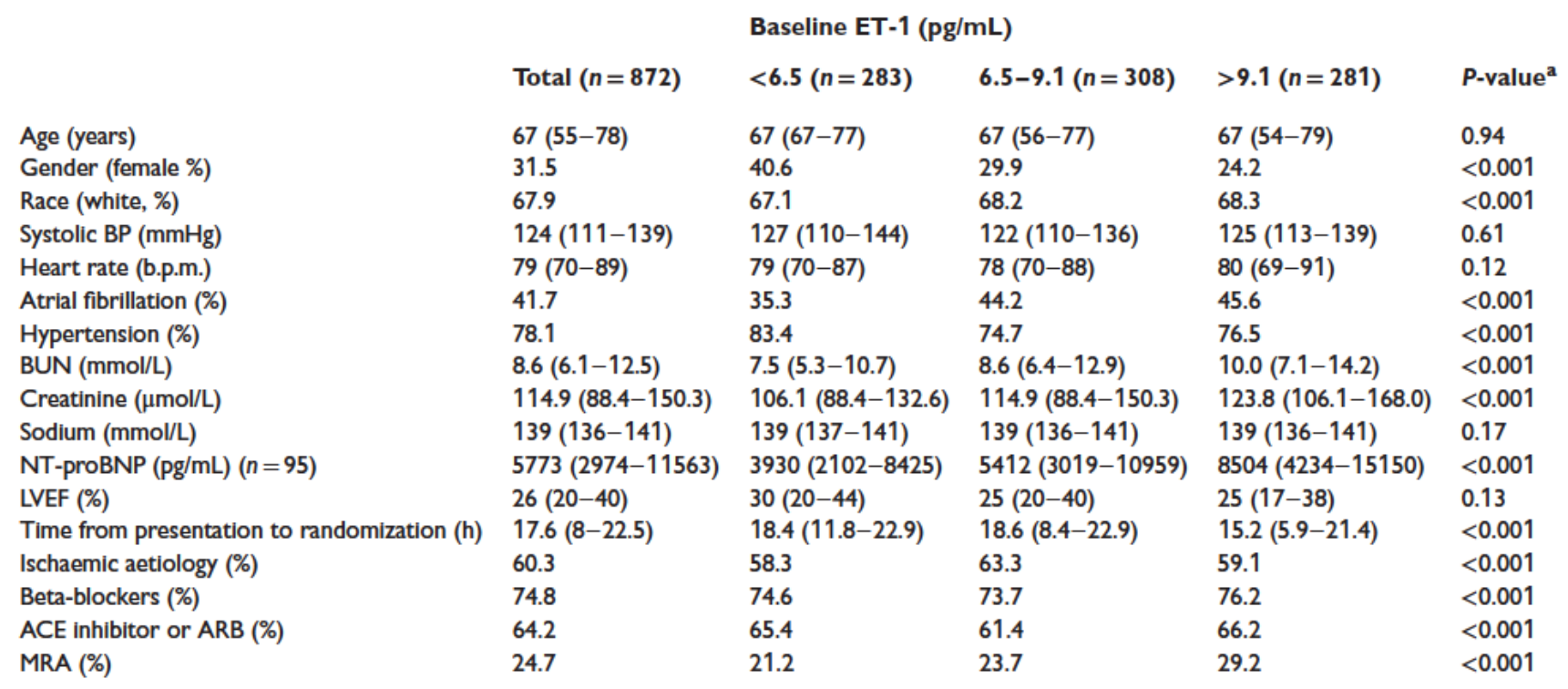

BP, blood pressure; BUN, blood urea nitrogen; ET-1, endothelin-1; MRA, mineralocorticoid receptor antagonist.

${ }^{a}$ P-value from test of trend (Jonckheere-Terpstra test for continuous and Cochran-Armitage test for categorical variables); continuous variables expressed as median (Q1-Q3).

\section{Results}

\section{Study population and serial endothelin-1 measurements}

The ASCEND-HF biomarker substudy population was not significantly different from the main ASCEND-HF trial population, except that $88 \%$ of substudy patients were enrolled in North America (43\% in the overall trial). Median baseline ET-1 was $7.6 \mathrm{pg} / \mathrm{mL}$ (IQR $5.9-10.0 \mathrm{pg} / \mathrm{mL}$ ). Baseline characteristics of our substudy cohort stratified by baseline ET-1 tertiles are displayed in Table 1. In contrast, median ET-1 levels were significantly lower than baseline when measured at $48-72 \mathrm{~h}[6.3 \mathrm{pg} / \mathrm{mL}$ (IQR $4.9-8.1 \mathrm{pg} / \mathrm{mL}), P<0.001$ vs. baseline $]$ and at 30 days $[5.9 \mathrm{pg} / \mathrm{mL}$ (IQR 4.7-7.9 pg/mL), $P<0.001$ vs. baseline). ET-1 levels were significantly higher in those who presented with $\mathrm{EF}<50 \%$ vs. $>50 \%$ [7.8 pg/mL (IQR 6-10.1 pg/mL) vs. 7.0 pg/mL (IQR 5.4-9.1 pg/mL), $P=0.033$ ]. Of 872 patients at baseline, $3 \%$ had died at 30 days; $11.5 \%$ had died or were rehospitalized by 30 days; $11.7 \%$ had died at 180 days; and $4.9 \%$ died or experienced worsening heart failure prior to discharge (Supplementary material online, Table S2).

\section{Association between endothelin-1 levels and adverse clinical outcomes}

Figure 1 shows the association between baseline, $48-72 \mathrm{~h}$, and 30-day ET-1 and 180-day all-cause mortality. Patients in the highest tertile of baseline ET-1 levels (>9.1 pg/mL) had a 3.2-fold increased mortality risk at 180 days [tertile 3 vs. 1, HR 3.2, 95\% confidence interval $(\mathrm{Cl}) 1.9-5.5, P<0.001]$. This risk persisted if ET-1 levels were maintained at the highest tertile at $48-72 \mathrm{~h}(>7.3 \mathrm{pg} / \mathrm{mL}$; HR 3.16, 95\% Cl 1.7-6.1, $P<0.001)$ and at 30 days $(>6.9 \mathrm{pg} / \mathrm{mL}$; HR 2.7, 95\% Cl 1.3-5.6, P<0.001). As a continuous variable, log-transformed ET-1 levels at baseline, $48-72 \mathrm{~h}$, and 30 days were also all significantly associated with 180-day mortality (HR per log 1.76, 95\% Cl 1.4-2.2, P<0.001; HR per log 1.65, 95\% Cl 1.3-2.1, $P<0.001 ; \mathrm{HR}$ per $\log 1.5,95 \% \mathrm{Cl} 1.1-2.0, P=0.004$, respectively; Figure 2; Table 2).

After adjusting for pre-specified covariates from the ASCEND-HF risk model, ET-1 levels at baseline and at $48-72 \mathrm{~h}$ were independently associated with 180-day mortality (HR per log 1.6, 95\% Cl 1.3-2.0, $P<0.001 ; \mathrm{HR}$ per $\log 1.5,95 \% \mathrm{Cl} 1.2-1.9$, $P=0.001$, respectively). There was no independent association with death at 30 days and death or rehospitalization at 30 days. Upon adding baseline NT-proBNP to the ASCEND-HF risk model, ET-1 remained independently associated with 180-day mortality at baseline (HR per log 1.4, 95\% Cl 1.1-1.7, $P=0.003$, Table 2) and at $48-72 \mathrm{~h}(\mathrm{HR}$ per $\log 1.4,95 \% \mathrm{Cl} 1.1-1.8, P=0.004$, Table 2). ET-1 increases the c-statistic of the ASCEND-HF risk model for 180-day mortality (age, systolic blood pressure, and BUN) from $73.4 \%$ to $76.2 \%(P=0.07)$. IDI was $19 \%(P<0.001)$. In category-free net reclassification analysis, adding baseline ET-1 levels to the ASCEND-HF risk model correctly reclassifies a net $34.2 \%$ of patients $(P<0.001$, Supplementary material online. Table S4). When ET-1 and NT-proBNP are added to the ASCEND-HF risk model in NRI analysis, a net $48.6 \%$ of patients are reclassified $(P<0.001$, Supplementary material onlin, Table S4).

Among the patients with baseline NT-proBNP less than the cohort median ( $<5773 \mathrm{pg} / \mathrm{mL}$ ), 180-day mortality was not different whether their baseline ET-1 level was above $(>7.6 \mathrm{pg} / \mathrm{mL})$ or below the median (6.4\% and 6.2\%, respectively; Figure 3). However, among 

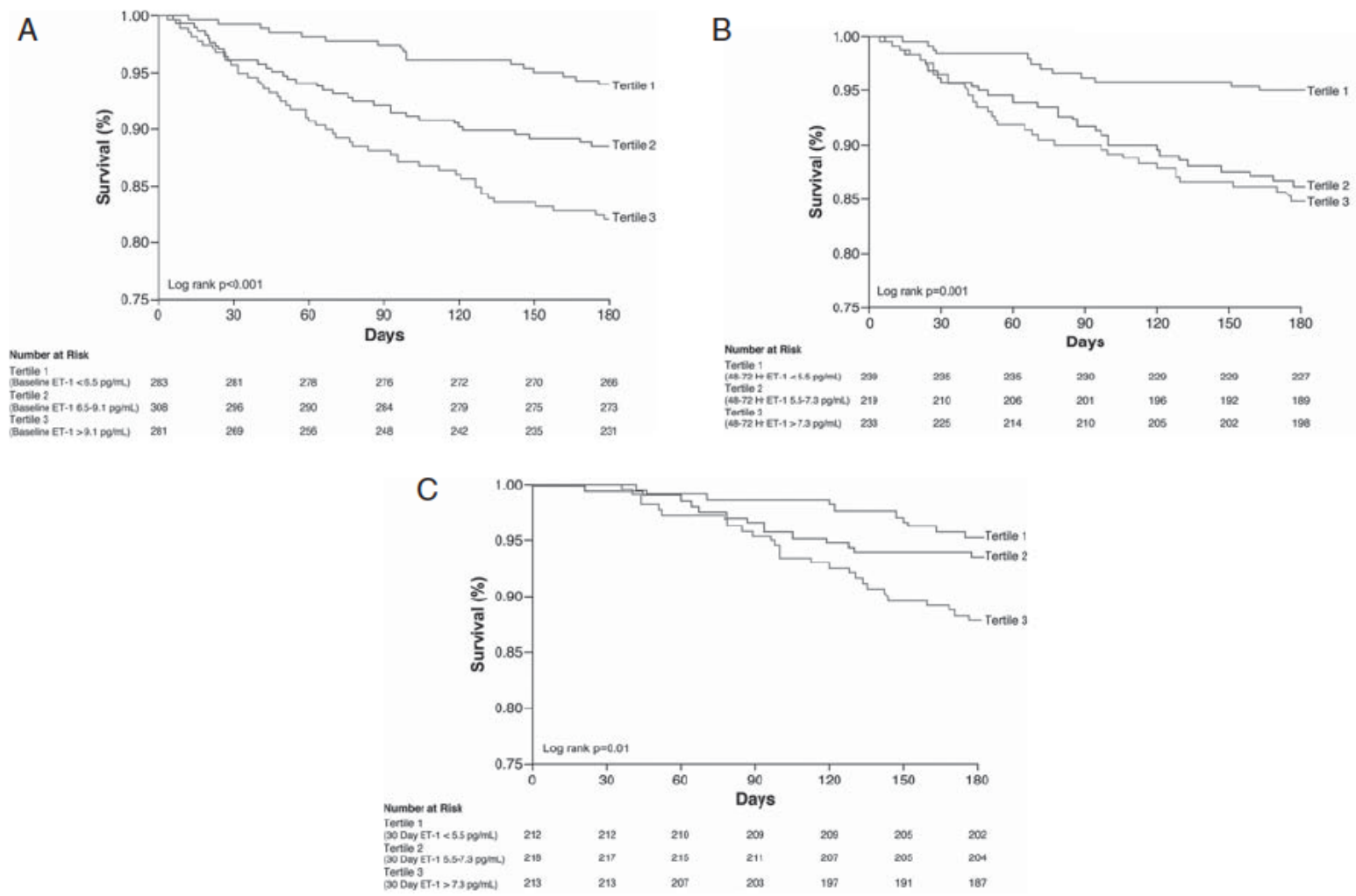

Figure 1 Survival at 180 days stratified by baseline, 48-72 h, and 30-day plasma endothelin-1 (ET-1) levels. Kaplan-Meier analysis for 180-day survival stratified by tertiles of: $(A)$ baseline (tertile ranges: tertile $1,<6.5$; tertile $2,6.5-9.1$; tertile $3,>9.1$ ); (B) $48-72$ h (tertile ranges: tertile 1, <5.5; tertile 2, 5.5-7.3; tertile 3, >7.3); and (C) 30-day plasma ET-1 levels in pg/mL (tertile ranges: tertile 1, <5.1; tertile 2, 5.1-6.9; tertile $3,>6.9)$.

those with greater than median baseline NT-proBNP, there was a $7.3 \%$ absolute difference in 180-day mortality between patients with ET-1 above and below the cohort median (Figure 3; log rank $P<0.001)$. There was no significant interaction between ET-1 and NT-proBNP in this analysis (HR 1.12, 95\% Cl 0.97-1.3, $P=0.13$ ). In addition, there was a trend towards an independent association between 30-day ET- 1 levels and death at 180 days (HR per log 1.4, $95 \% \mathrm{Cl} 0.98-2.0, P=0.063$ ).

Baseline and 48-72 h ET-1 levels were also associated with death or rehospitalization at 30 days in unadjusted analysis (HR per $\log 1.3,95 \% \mathrm{Cl} 1.0-1.5, P=0.017$; HR 1.3, 95\% Cl 1.1-1.7, $P=0.014$, respectively; Table 2). ET-1 measured at $48-72 \mathrm{~h}$ was also found to be independently associated with death or worsening heart failure prior to discharge (OR per log 1.56, 95\% Cl 1.04-2.36, $P=0.032$ ) when adjusted for the ASCEND-HF risk model. This independent association remained when baseline NT-proBNP was added to the ASCEND-HF risk model (OR per $\log 1.58,95 \% \mathrm{Cl} 1.03-2.43, P=0.035$; Table 2).

In an effort to ascertain the variable importance of ET-1 in comparison with other experimental biomarkers for acute heart failure, we completed a multimarker Cox proportional hazards model of ET-1, NT-proBNP, cTnl, hsCRP, and cystatin C measured at the time of hospitalization (Table 3). ${ }^{17-19}$ ET-1 and NT-proBNP were found to be independently associated with 180-day mortality. This analysis shows that, when assessed in the context of these other biomarkers, ET-1 provides additional and independent prognostic information on 180-day mortality after acute heart failure hospitalization.

\section{Association between changes in endothelin-1 levels from baseline and adverse clinical outcomes}

We further assessed the relationship between changes in ET-1 from baseline to $48-72 \mathrm{~h}$ and adverse clinical outcomes (Supplementary material online, Table S5). Multivariable analysis revealed that absolute change in ET-1 levels from baseline to $48-72 \mathrm{~h}$ was independently associated with death or worsening heart failure prior to discharge (OR per $\log 1.46,95 \% \mathrm{Cl} 1.03-2.08$, $P=0.034$ ). Change in ET-1 from baseline to $48-72 \mathrm{~h}$ was also independently associated with this outcome when NT-proBNP was included as a covariate (OR per $\log 1.5,95 \% \mathrm{Cl} 1.05-2.14$, $P=0.027$, respectively). However, changes in ET- 1 from baseline to $48-72 \mathrm{~h}$ and from baseline to 30 days were not associated with 180-day mortality (Supplementary material online, Table S5). 

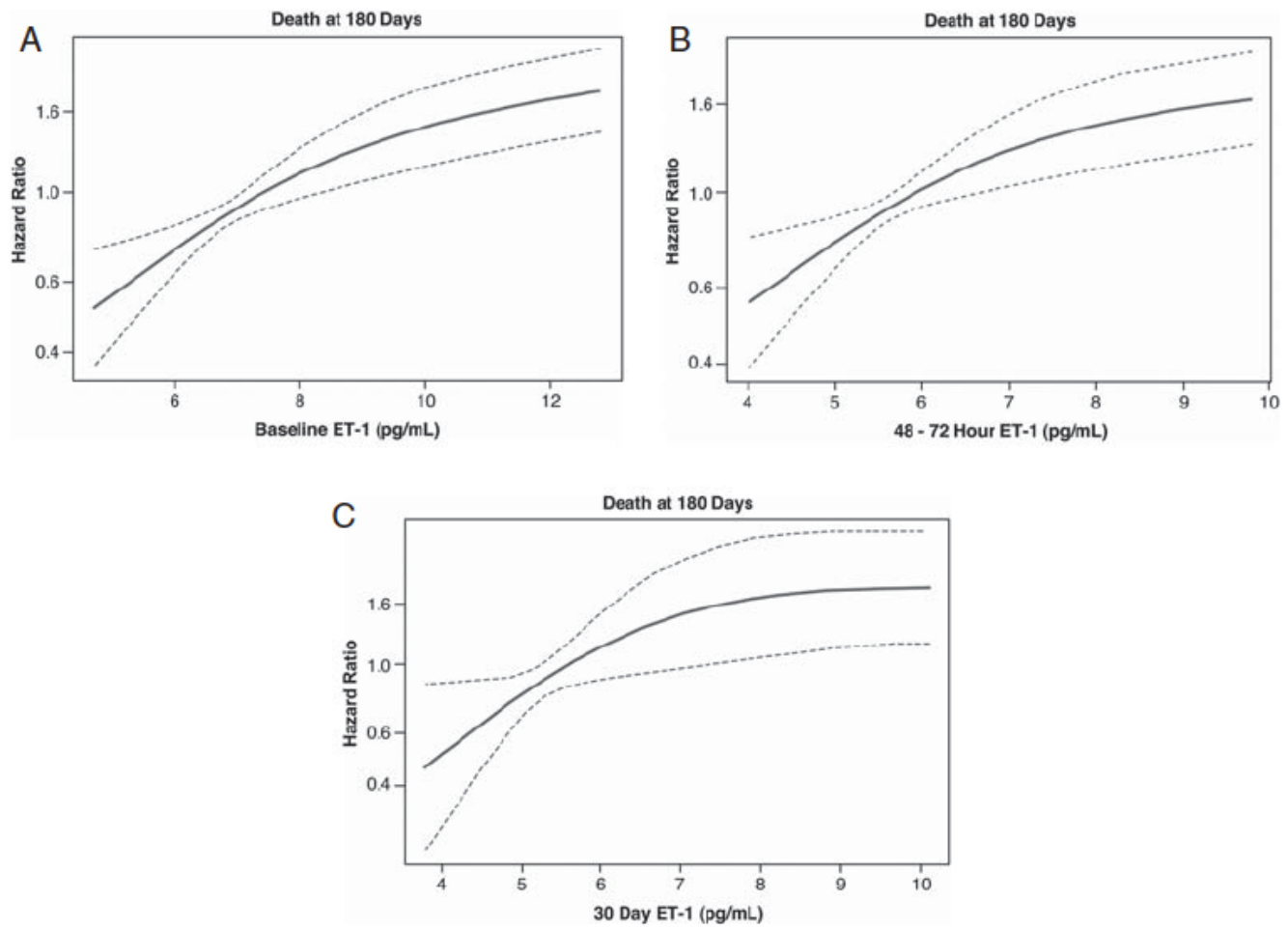

Figure 2 Death at 180 days vs. baseline, 48-72 h, and 30-day endothelin-1 (ET-1) level. Cubic spline plots of death at 180 days vs. (A) baseline ET-1; (B) 48-72 h ET-1; and (C) 30-day ET-1. Baseline, 48-72 h, and 30-day ET-1 levels $>7.4 \mathrm{pg} / \mathrm{mL}, 6.0 \mathrm{pg} / \mathrm{mL}$, and 5.6 pg/mL, respectively, correspond to a hazard ratio of death at 180 days $>1$.

\section{Endothelin-1 and nesiritide}

Table S6 in the Supplementary material online shows the effects of nesiritide vs. placebo therapy on baseline, 48-72 h, and 30-day ET-1 levels. At baseline and at 30 days, patients treated with nesiritide vs. placebo have similar ET-1 levels $(P=0.66$ and $P=$ 0.51 , respectively). Interestingly, at $48-72 \mathrm{~h}$, those treated with nesiritide had a higher ET-1 level when compared with placebo [nesiritide, $6.6 \mathrm{pg} / \mathrm{mL}$ (IQR 5.4, 8.5) vs. placebo, $5.9 \mathrm{pg} / \mathrm{mL}$ (4.6, 7.6), $P<0.0001$ ], with correspondingly less overall reduc-tion of ET-1 from baseline [nesiritide, -1.1 (IQR $-2.8,0.3)$ vs. placebo, $-1.8 \mathrm{pg} / \mathrm{mL}(\mathrm{IQR}-3.5,-0.4), P=0.0002]$. Nevertheless, changes in ET-1 levels were not different by 30 days between the groups ( $P$ $=0.85$ ). These results were consistent in patients with NTproBNP below and above the cohort median.

\section{Discussion}

There are several major findings in this ASCEND-HF biomarker substudy. First, we confirmed that circulating ET-1 is increased in ADHF and decreases after stabilization with medical therapy during 30-day follow-up. Secondly, baseline plasma ET-1 is independently associated with 180-day mortality, providing additional prognostic information to that yielded by NT-proBNP. Our data suggest that this additional prognostic information is most pronounced in patients with an NT-proBNP above our cohort median of $5773 \mathrm{pg} / \mathrm{mL}$. Thirdly, persistently elevated ET-1 at $48-72 \mathrm{~h}$ in ADHF is independently associated with increased in-hospital mortality or worsening heart failure, as well as 180 -day mortality. Fourthly, ET-1 remains independently associated with 180-day morality in ADHF when multimarker Cox proportional hazards analysis including NT-proBNP, cTnl, hsCRP, and cystatin C is performed. Lastly, therapy with nesiritide did not result in a greater reduction in ET-1 levels, when compared with standard medical therapy alone. In fact, those patients treated with nesiritide experienced a smaller decrease in ET-1 than those treated with standard therapy. Taken together, our data demonstrate that plasma ET-1 is an independent prognosticator for death and in-hospital outcomes in acute heart failure that provides supplemental information to that provided by other heart failure biomarkers.

Endothelin-1 is a 21 amino acid neurohormone that serves as a highly potent endogenous vasoconstrictor that was first isolated from aortic endothelial cell culture media in $1988 .{ }^{16}$ Located on chromosome 6, its production is up-regulated by thrombin, epinephrine, angiotensin II, cortisol, inflammatory cytokines, hypoxia, vascular shear stress, and insulin. ET-1 transcription is inhibited by both endogenous and exogenous vasodilators including nitric oxide, and is produced by endothelial and smooth muscle cells in blood vessels, cardiomyocytes, macrophages, fibroblasts, airway epithelium, central nervous system neurons, and pancreatic islet cells. ${ }^{17}$ Secreted ET-1 binds ET receptors (A and B) on vascular smooth muscle resulting in increased intracellular calcium and 
Table 2 Endothelin-1 levels and intermediate and long-term outcomes

\begin{tabular}{|c|c|c|c|c|c|c|}
\hline \multirow[t]{2}{*}{ Outcome } & \multicolumn{2}{|l|}{ Unadjusted $^{\mathbf{a}}$} & \multicolumn{2}{|l|}{ Adjusted model $1^{\mathrm{b}}$} & \multicolumn{2}{|c|}{ Adjusted model $2^{c}$} \\
\hline & OR/HR $(95 \% \mathrm{Cl})$ & $P$-value & OR/HR $(95 \% \mathrm{Cl})$ & $P$-value & OR/HR $(95 \% \mathrm{Cl})$ & $P$-value \\
\hline \multicolumn{7}{|l|}{ Baseline ET-1 } \\
\hline Death at 30 days (HR) & $1.5(1.1-2.1)$ & 0.006 & $1.43(1.0-2.0)$ & 0.03 & $1.25(0.92-1.7)$ & 0.15 \\
\hline Death/rehospitalization at 30 days (HR) & $1.3(1.0-1.5)$ & 0.02 & $1.1(0.95-1.4)$ & 0.16 & $1.0(0.87-1.2)$ & 0.69 \\
\hline Death at 180 days (HR) & $1.76(1.4-2.2)$ & $<0.001$ & $1.6(1.3-2.0)$ & $<0.001$ & $1.4(1.1-1.7)$ & 0.003 \\
\hline Death or worsening HF prior to discharge (OR) & $1.2(0.83-1.6)$ & 0.37 & $1.1(0.77-1.5)$ & 0.71 & $0.98(0.70-1.4)$ & 0.93 \\
\hline \multicolumn{7}{|l|}{$48-72$ h ET-1 } \\
\hline Death at 30 days & $1.4(0.87-2.3)$ & 0.17 & $1.2(0.71-2.0)$ & 0.50 & $1.2(0.69-1.9)$ & 0.60 \\
\hline Death/rehospitalization at 30 days & $1.3(1.1-1.7)$ & 0.014 & $1.2(0.94-1.5)$ & 0.15 & $1.2(0.95-1.5)$ & 0.14 \\
\hline Death at 180 days & $1.65(1.3-2.1)$ & $<0.001$ & $1.5(1.2-1.9)$ & 0.001 & $1.4(1.1-1.8)$ & 0.004 \\
\hline Death or worsening HF prior to discharge & $1.8(1.2-1.6)$ & 0.003 & $1.6(1.03-2.4)$ & 0.03 & $1.58(1.03-2.4)$ & 0.04 \\
\hline \multicolumn{7}{|l|}{ 30-day ET-1 } \\
\hline Death at 180 days & $1.5(1.1-2.0)$ & 0.004 & $1.4(0.98-2.0)$ & 0.06 & $1.30(0.91-1.9)$ & 0.15 \\
\hline
\end{tabular}

ASCEND-HF, Acute Study of Clinical Effectiveness of Nesiritide in Decompensated Heart Failure; Cl, confidence interval; ET-1,endothelin-1; HF, heart failure; HR, hazard ratio; OR, odds ratio.

aUnadjusted: log-transformed (ET-1).

${ }^{b}$ Adjusted model 1: log-transformed (ET-1), adjusted with all risk covariates from the ASCEND-HF risk model (Supplementary material online, Table S1). Covariates for death at 180 days were age, systolic blood pressure $<140 \mathrm{mmHg}$, and blood urea nitrogen.

'Adjusted model 2: log-transformed (ET-1), adjusted with all risk covariates from ASCEND-HF risk model and log-transformed NT-proBNP.

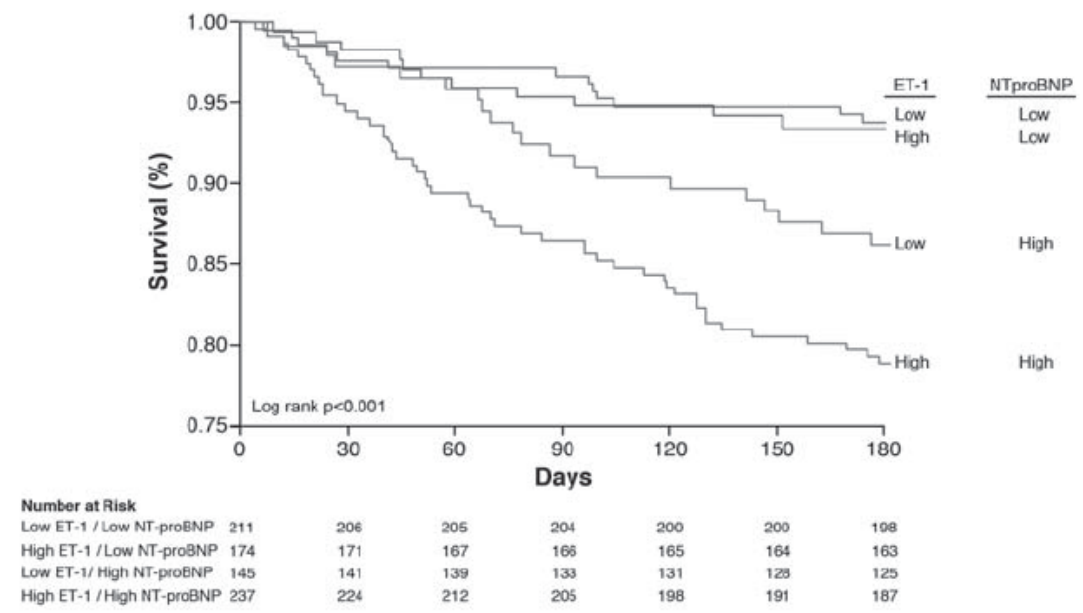

Figure 3 Survival at 180 days stratified by median baseline endothelin-1 (ET-1) and NT-proBNP levels. Kaplan-Meier analysis for 180-day survival stratified by median baseline ET-1 and NT-proBNP levels. Baseline median ET-1 was $7.6 \mathrm{pg} / \mathrm{mL}$; the median level for NT-proBNP was $5773 \mathrm{pg} / \mathrm{mL}$. 'High' refers to values above the median, while 'low' refers to values below the median.

vasoconstriction. ${ }^{18,19}$ Conversely, activation of ET receptor B on the surface of endothelial cells results in nitric oxide production and smooth muscle cell relaxation. ${ }^{20}$ In heart failure patients, ET receptor $A$ is up-regulated, while ET receptor $B$ is down-regulated. ET-1 exacts its systemic effects via autocrine and paracrine pathways. ${ }^{17,21}$ In the subset of ADHF patients with elevated ET-1, it may be possible that endothelin-mediated vasoconstriction contributes to their excess mortality and adverse clinical outcomes, in comparison with those with lower ET-1 levels. Therefore, elevated ET-1 may identify a group of patients with ADHF who are at particular risk for both short- and long-term worse outcomes.
Endothelin-1 provides additional prognostic information in ADHF that enhances information provided by NT-proBNP. In fact, among patients whose baseline NT-proBNP was above the median, ET-1 provided significant mortality prognostic information (Figure 3). Within this subgroup, those with ET-1 above the median experienced 180 -day mortality of $21.1 \%$, while those below median ET-1 experienced 13.8\% mortality. Therefore, among those with significant NT-proBNP elevation in ADHF, measuring ET-1 can distinguish between two populations which in our cohort experienced a $53 \%$ difference in relative mortality $\mathbf{( 7 . 3 \%}$ absolute difference) at 180 days after hospitalization. 
Table 3 Multimarker Cox proportional hazards model for 180-day mortality after acute heart failure hospitalization

$\begin{array}{lll} & \begin{array}{l}\text { HR per SD } \\ \text { increase }(95 \% \mathrm{CI})\end{array} & \text { P-value } \\ \text { Log-transformed ET-1 } & 1.43(1.14-1.8) & 0.002 \\ \text { SBP }<140 \mathrm{mmHg} & 1.39(0.77-2.52) & 0.28 \\ \text { Age } & 1.81(1.35-2.43) & <0.001 \\ \text { Log-transformed BUN } & 1.29(0.94-1.76) & 0.11 \\ \text { Log-transformed hsCRP } & 1.17(0.95-1.42) & 0.13 \\ \text { Log-transformed cTnl } & 1.16(0.94-1.45) & 0.17 \\ \text { Log-transformed NT-proBNP } & 1.36(1.05-1.76) & 0.02 \\ \text { Log-transformed cystatin C } & 1.05(0.78-1.41) & 0.75\end{array}$

All variables were measured at the time of hospitalization $(n=727)$. Variables were log-transformed as indicated in the text due to non-normal distributions in our cohort.

BUN, blood urea nitrogen; $\mathrm{Cl}$, confidence interval; cTnl, cardiac troponin I; ET-1, endothelin-1; HR, hazard ratio; hsCRP, high-sensitivity C-reactive protein; SBP, systolic blood pressure; SD, standard deviation;

The endothelin system has been the focus of basic and clinical studies investigating therapies for cardiopulmonary disease. Endothelin receptor antagonists have become a major therapeutic category for pulmonary arterial hypertension. ${ }^{22}$ Prior research has identified a significant association between plasma ET-1 and pulmonary vascular resistance, central venous pressure, and oxygen saturation in pulmonary arterial and venous hypertension. ${ }^{23}$ Endothelin receptor antagonists have previously been investigated as therapy for acute heart failure, with considerably less success. ${ }^{24-28}$ The Randomized Intravenous TeZosentan (RITZ) trials, for example, failed to show a benefit of therapy with the endothelin receptor antagonist tezosentan for a series of outcomes in acute heart failure patients, including the composite endpoint of death, worsening heart failure, recurrent ischaemia, or recurrent or new myocardial infarction at $\mathbf{7 2} \mathrm{h}$, although improvement in cardiac index and decrease in PCWP were demonstrated. However, none of these trials analysed outcomes stratified by baseline plasma ET-1 levels; it may be possible that patients with high ET-1 levels experience benefit from this class of medical therapy.

In addition, the investigational drug serelaxin, a relaxin receptor agonist, is known to bind the endothelin B receptor on vascular endothelium, which significantly decreases ET-1 production and contributes to vasodilatation. ${ }^{9}$ ET-1 quantification may identify a subset of ADHF patients who benefit from therapy targeting endothelin production and signalling. Further investigation into the possible therapeutic effects of relaxin receptor agonists such as serelaxin and endothelin receptor antagonists in ADHF patients with high ET-1 levels is warranted.

Nesiritide is a recombinant natriuretic peptide that mimics BNP, which is known to counteract physiologically the effects of endothelin-mediated vasoconstriction. ${ }^{29,30}$ Given that both BNP and ET-1 are elevated in ADHF, nesiritide-mediated vasodilatation may mimic heart failure pathophysiology and result in a compensatory increased systemic release of ET-1, although the median net effect of standard medical therapy is reduction in plasma ET-1 levels. However, the clinical implications of this finding, and whether this applies to other vasoactive therapies, remain uncertain. Vasoactive responses that counteract volume removal and vasodilation with nesiritide may play a role in the observed lesser acute reduction of ET-1 over time, but such a difference was not sustained over time and did not appear to impact long-term outcomes.

\section{Study limitations}

Our analysis has several limitations which should be considered. First, this is a retrospective study with only three sample collection time points, and therefore may not provide a complete picture of ET-1 changes with therapy. Among study subjects from whom we measured baseline ET-1, only 26 of 872 patients had died at 30 days; as a result, our analysis may be underpowered for short-term mortality. Baseline and 48-72 h ET-1 were not independently associated with 30-day mortality, or 30-day mortality or rehospitalization. There was also no independent association between 30-day ET-1 and 180-day mortality. These neutral findings are probably related to lower event rates, although examining multiple time points and endpoints increases the likelihood of finding false associations that represent chance. We also did not have invasive measurements in our subjects to examine the degree of pulmonary hypertension or vasoactive responses to therapy. Despite these limitations, serial ET-1 measured in hospitalized ADHF patients may yield prognostic information on mortality and adverse in-hospital outcomes that is independent of and supplemental to information provided by other established heart failure biomarkers, including NT-proBNP. Based on the hypothesis-generating findings presented here, ET-1's potential clinical utility warrants further investigation.

\section{Supplementary Information}

Additional Supporting Information may be found in the online version of this article:

Table S1 Outcome covariates.

TableS2Baseline characteristics and outcomes in ET-1 biomarker substudy subjects compared with the non-biomarker substudy ASCEND-HF population.

Table S3 ET-1 levels and intermediate and long-term outcomes, adjusted with additional covariates.

Table S4 Added discrimination and event-specific reclassification of ET-1 levels on 180-day mortality.

Table S5 Short-term change in ET-1 and intermediate and long-term outcomes.

Table S6 Impact of nesiritide therapy on serial changes in ET-1 levels.

\section{Funding}

This work was supported by Scios Inc. Janssen Research \& Development LLC retains operational responsibility for the ASCEND-HF study and its biomarker substudy. Singulex, Inc. performed all plasma endothelin- 1 assays, and was blinded from the trial database 
or analyses. Statistical analyses and manuscript preparation were conducted independently of the sponsors, and the authors have access to all the data in their entirety and approved the final manuscript.

Conflict of interest: A.F.H. reports a research grant (significant) from Johnson \& Johnson; J.B. reports being a consultant/advisory board member (modest) for Johnson \& Johnson; M.M. reports being a consultant/advisory board member (modest) for Bayer, Novartis, and Servier; G.M.F. reports research grants (significant) from Johnson \& Johnson, Roche Diagnostics, Critical Diagnostics, and BG Medicine; A.A.V. reports being a consultant/advisory board member (modest) for Johnson \& Johnson, Alere, Bayer, Boehringer Ingelheim, Cardio3Biosciences, Celladon, Merck/MSD, Novartis, Servier, Trevena, and Vifor Pharma; J.J.M. reports a research grant (significant) from Johnson \& Johnson; P.W.A. reports research grants (significant) from Johnson \& Johnso and Ortho Biotech; R.C.S. reports other research support (modest) from Johnson \& Johnson; consultant/advisory board (modest) from Johnson \& Johnson; C.M.O. reports a research grant (significant) from Johnson \& Johnson. All other authors have no conflicts to declare.

\section{References}

1. Cody RJ, Haas G], Binkley PF, Capers Q, Kelley R. Plasma endothelin correlates with the extent of pulmonary hypertension in patients with chronic congestive heart failure. Circulation 1992;85:504-509.

2. Giaid A, Yanagisawa M, Langleben D, Michel RP, Levy R, Shennib H, Kimura S, Masaki T, Duguid WP, Stewart DJ. Expression of endothelin-1 in the lungs of patients with pulmonary hypertension. N Engl J Med 1993;328:1732-1739.

3. Taddei S, Virdis A, Ghiadoni L, Sudano I, Notari M, Salvetti A. Vasoconstriction to endogenous endothelin-1 is increased in the peripheral circulation of patients with essential hypertension. Circulation 1999;100:1680-1683.

4. McMurray لJ, Ray SG, Abdullah I, Dargie HJ, Morton J]. Plasma endothelin in chronic heart failure. Circulation 1992;85:1374-1379.

5. Lerman A, Kubo SH, Tschumperlin LK, Burnett JC Jr. Plasma endothelin concentrations in humans with end-stage heart failure and after heart transplantation. J Am Coll Cardiol 1992;20:849-853.

6. Omland T, Lie RT, Aakvaag A, Aarsland T, Dickstein K. Plasma endothelin determination as a prognostic indicator of 1-year mortality after acute myocardial infarction. Circulation 1994;89:1573-1579.

7. Pousset F, Isnard R, Lechat P, Kalotka H, Carayon A, Maistre G, Escolano S, Thomas D, Komajda M. Prognostic value of plasma endothelin-1 in patients with chronic heart failure. Eur Heart J 1997;18:254-258.

8. Hulsmann M, Stanek B, Frey B, Sturm B, Putz D, Kos T, Berger R, Woloszczuk W, Maurer G, Pacher R. Value of cardiopulmonary exercise testing and big endothelin plasma levels to predict short-term prognosis of patients with chronic heart failure. J Am Coll Cardiol 1998;32:1695-1700.

9. Dschietzig T, Bartsch C, Richter C, Laule M, Baumann G, Stangl K. Relaxin, a pregnancy hormone, is a functional endothelin-1 antagonist attenuation of endothelin-1-mediated vasoconstriction by stimulation of endothelin type-B receptor expression via ERK-1/2 and nuclear factor-kappaB. Circulation Res 2003;92:32-40.

10. O'Connor CM, Starling RC, Hernandez AF, Armstrong PW, Dickstein K, Hasselblad V, Heizer GM, Komajda M, Massie BM, McMurray J], Nieminen MS, Reist C], Rouleau JL, Swedberg K, Adams KF, Jr., Anker SD, Atar D, Battler A, Botero R, Bohidar NR, Butler J, Clausell N, Corbalan R, Costanzo MR, Dahlstrom U, Deckelbaum LI, Diaz R, Dunlap ME, Ezekowitz JA, Feldman D, Felker GM, Fonarow GC, Gennevois D, Gottlieb SS, Hill JA, Hollander JE, Howlett JG, Hudson MP, Kociol RD, Krum H, Laucevicius A, Levy WC, Mendez GF, Metra M, Mittal S, Oh BH, Pereira NL, Ponikowski P, Tang WH, Tanomsup S, Teerlink JR, Triposkiadis F, Troughton RW, Voors AA, Whellan DJ, Zannad F, Califf RM. Effect of nesiritide in patients with acute decompensated heart failure. $N$ Engl J Med 2011;365:32-43.

11. Hernandez AF, O'Connor CM, Starling RC, Reist CJ, Armstrong PW, Dickstein K, Lorenz T], Gibler WB, Hasselblad V, Komajda M, Massie B, McMurray J],
Nieminen M, Rouleau JL, Swedberg K, Califf RM. Rationale and design of the Acute Study of Clinical Effectiveness of Nesiritide in Decompensated Heart Failure Trial (ASCEND-HF). Am Heart J 2009;157:271-277.

12. Felker GM, Hasselblad V, Tang WH, Hernandez AF, Armstrong PW, Fonarow GC, Voors AA, Metra M, McMurray IJ, Butler J, Heizer GM, Dickstein K, Massie BM, Atar D, Troughton RW, Anker SD, Califf RM, Starling RC, O'Connor CM. Troponin I in acute decompensated heart failure: insights from the ASCEND-HF study. Eur J Heart Fail 2012;14:1257-1264.

13. Kalogeropoulos AP, Tang WH, Hsu A, Felker GM, Hernandez AF, Troughton RW, Voors AA, Anker SD, Metra M, McMurray JJ, Massie BM, Ezekowitz JA, Califf RM, O'Connor CM, Starling RC, Butler J. High-sensitivity C-reactive protein in acute heart failure: insights from the ASCEND-HF trial. J Cardiac Fail 2014;20:319-326.

14. Tang WH, Dupont M, Hernandez AF, Voors AA, Hsu AP, Felker GM, Butler J, Metra M, Anker SD, Troughton RW, Gottlieb SS, McMurray JJ, Armstrong PW, Massie BM, Califf RM, O'Connor CM, Starling RC. Comparative assessment of short-term adverse events in acute heart failure with cystatin $C$ and other estimates of renal function: results from the ASCEND-HF trial. JACC Heart Fail 2015;3:40-49.

15. Todd J, Freese B, Lu A, Held D, Morey J, Livingston R, Goix P. Ultrasensitive flow-based immunoassays using single-molecule counting. Clin Chem 2007;53:1990-1995.

16. Yanagisawa M, Kurihara H, Kimura S, Tomobe $\mathrm{Y}$, Kobayashi M, Mitsui $\mathrm{Y}$, Yazaki $\mathrm{Y}$, Goto K, Masaki T. A novel potent vasoconstrictor peptide produced by vascular endothelial cells. Nature 1988;332:411-415.

17. Kawanabe Y, Nauli SM. Endothelin. Cell Mol Life Sci 2011; 68:195-203.

18. Arai H, Hori S, Aramori I, Ohkubo $\mathrm{H}$, Nakanishi S. Cloning and expression of a cDNA encoding an endothelin receptor. Nature 1990;348:730-732.

19. Sakurai T, Yanagisawa M, Takuwa Y, Miyazaki H, Kimura S, Goto K, Masaki T. Cloning of a cDNA encoding a non-isopeptide-selective subtype of the endothelin receptor. Nature 1990;348:732-735.

20. Luscher TF, Barton M. Endothelins and endothelin receptor antagonists: therapeutic considerations for a novel class of cardiovascular drugs. Circulation 2000;102:2434-2440.

21. Dupuis J, Stewart DJ, Cernacek P, Gosselin G. Human pulmonary circulation is an important site for both clearance and production of endothelin-1. Circulation 1996;94:1578-1584.

22. Channick RN, Simonneau G, Sitbon O, Robbins IM, Frost A, Tapson VF, Badesch DB, Roux S, Rainisio M, Bodin F, Rubin LJ. Effects of the dual endothelin-receptor antagonist bosentan in patients with pulmonary hypertension: a randomised placebo-controlled study. Lancet 2001;358:1119-1123.

23. Nootens M, Kaufmann E, Rector T, Toher C, Judd D, Francis GS, Rich S. Neurohormonal activation in patients with right ventricular failure from pulmonary hypertension: relation to hemodynamic variables and endothelin levels. J Am Coll Cardiol 1995; 26:1581-1585.

24. Torre-Amione G, Young JB, Durand J, Bozkurt B, Mann DL, Kobrin I, Pratt CM. Hemodynamic effects of tezosentan, an intravenous dual endothelin receptor antagonist, in patients with class III to IV congestive heart failure. Circulation 2001;103:973-980.

25. Torre-Amione G, Young JB, Colucci WS, Lewis BS, Pratt C, Cotter G, Stangl K, Elkayam U, Teerlink JR, Frey A, Rainisio M, Kobrin I. Hemodynamic and clinical effects of tezosentan, an intravenous dual endothelin receptor antagonist, in patients hospitalized for acute decompensated heart failure. J Am Coll Cardiol 2003;42:140-147.

26. O'Connor CM, Gattis WA, Adams KF Jr, Hasselblad V, Chandler B, Frey A, Kobrin I, Rainisio M, Shah MR, Teerlink J, Gheorghiade M. Tezosentan in patients with acute heart failure and acute coronary syndromes: results of the Randomized Intravenous TeZosentan Study (RITZ-4). J Am Coll Cardiol 2003;41:1452-1457.

27. Kaluski E, Kobrin I, Zimlichman R, Marmor A, Krakov O, Milo O, Frey A, Kaplan S, Krakover R, Caspi A, Vered Z, Cotter G. RITZ-5: randomized intravenous TeZosentan (an endothelin-A/B antagonist) for the treatment of pulmonary edema: a prospective, multicenter, double-blind, placebo-controlled study. J Am Coll Cardiol 2003;41:204-210.

28. McMurray JJ, Teerlink JR, Cotter G, Bourge RC, Cleland JG, Jondeau G, Krum H, Metra M, O'Connor CM, Parker JD, Torre-Amione G, van Veldhuisen DJ, Lewsey J, Frey A, Rainisio M, Kobrin I. Effects of tezosentan on symptoms and clinical outcomes in patients with acute heart failure: the VERITAS randomized controlled trials. JAMA 2007;298:2009-2019.

29. Bianciotti LG, de Bold AJ. Modulation of cardiac natriuretic peptide gene expression following endothelin type $A$ receptor blockade in renovascular hypertension. Cardiovasc Res 2001; 49:808-816.

30. Kohno M, Yokokawa K, Horio T, Yasunari K, Murakawa K, Takeda T. Atrial and brain natriuretic peptides inhibit the endothelin-1 secretory response to angiotensin II in porcine aorta. Circ Resh 1992;70:241-247. 